\title{
ANÁLISE DOS ATRIBUTOS FÍSICO-AMBIENTAIS DO MUNICÍPIO DE PRAIA GRANDE-SP
}

\section{Analysis of physical and environmental attributes of Praia Grande-SP}

\author{
Tissiana Almeida Souza \\ Doutoranda em Geografia, IG-Unicamp \\ tissisouza@gmail.com \\ Cenira Maria Lupinacci Cunha \\ Profa. Doutora, Deplan - IGCE, Unesp, Campus Rio Claro \\ cenira@rc.unesp.br
}

Artigo recebido em 11/09/2011 e aceito para publicação em 28/05/2012

RESUMO: As regiões litorâneas caracterizam-se como sistemas ambientais complexos e de delicado equilíbrio, em razão da interação entre o ambiente terrestre e o marinho. O município de Praia Grande apresenta características físico-ambientais diferenciadas em razão da presença da Serra do Mar e da Planície Quaternária. Estes dois sistemas, apesar de bastante distintos em suas singularidades, estão interligados através dos processos de circulação de matéria e energia. Com base na Teoria Geral dos Sistemas, o objetivo deste trabalho é analisar os atributos físico-ambientais do município de Praia Grande, a fim de avaliar quais áreas do município estão mais vulneráveis aos impactos provocados pela ação humana. Os dados para tal análise foram obtidos através da interpretação de dados morfométricos, geológicos, pedológicos, geomorfológicos e de uso da terra, organizados na forma de cartas elaboradas em escala 1:50.000.

Palavras-chave: Praia Grande, Planície Costeira ou Quaternária, Serra do Mar, atributos físico-ambientais.

ABSTRACT: The coastal regions are characterized as complex environmental systems with a delicate balance due to the interaction between terrestrial and marine environments. Praia Grande city presents differentiated physical and environmental characteristics due to the presence of Serra do Mar mountain chain and Quaternary Plains. These two systems are very distinct in their singularities but are interconnected through the circulation of matter and energy. Based on the General Theory of Systems, the objective of this study is to analyze the physical and environmental attributes of Praia Grande city in order to evaluate which areas are more vulnerable to the impacts caused by human action. Data for this analysis was obtained through the interpretation of morphometric, geological, pedological, geomorphological and land use data, organized in maps elaborated in 1:50.000 scale.

Key- words: Praia Grande, Coastal or Quaternary Plains, Serra do Mar mountain chain, physical-environmental attributes. 


\section{INTRODUÇÃO}

Os sistemas ambientais naturais apresentam diferentes graus de fragilidade em razão de suas características originais. As regiões litorâneas compreendem sistemas ambientais complexos e de delicado equilíbrio, nos quais ocorre interação entre o ambiente terrestre e o marinho, o que propicia a presença de elementos naturais únicos, como manguezais, praias, dunas e lagunas costeiras.

No Brasil, cerca de $20 \%$ da população habita o litoral, o que resulta, em diversas regiões, no adensamento populacional. No estado de São Paulo, a Região Metropolitana da Baixada Santista abriga cerca de 1,4 milhões de pessoas, cerca de $4 \%$ da população do estado. Em temporadas de verão e no carnaval, a população nos municípios da Baixada Santista atinge mais que o dobro da população residente (EMPLASA, 2002).

É neste contexto que se insere o município de Praia Grande, que se caracteriza por uma urbanização linear extensiva junto às praias (AFONSO, 2006), com a presença de loteamentos para lazer e/ou segunda residência. Aliado a este fato, considera-se que as regiões litorâneas apresentam suscetibilidade ambiental devido às suas características intrínsecas, como propriedades litológicas, pedológicas, geomorfológicas, climáticas e vegetacionais.

A intensa urbanização desconsiderou o ambiente original e eliminou a cobertura vegetal, alterou a topografia, modificou o padrão de drenagem e a permeabilidade do solo. Entretanto, o município ainda abriga ecossistemas naturais importantes, como a Mata Atlântica nas áreas serranas, os manguezais e a vegetação de restinga, que se encontram fortemente pressionados pela ação antrópica.

Diante destas considerações, o objetivo deste trabalho é analisar, a partir da abordagem sistêmica, os atributos físico-ambientais do município de Praia Grande, através da interpretação de dados morfométricos, geológicos, pedológicos, geomorfológicos e de uso da terra, organizados na forma de cartas elaboradas em escala 1:50.000. Considera-se que, através da interpretação destes dados, é possível compreender quais áreas do município estão mais vulneráveis à ação humana.

\section{LOCALIZAÇÃO E CARACTERIZAÇÃO FÍSI- CA DA ÁREA DE ESTUDO}

O município de Praia Grande localiza-se no litoral centro-sul do estado de São Paulo, entre as coordenadas geográficas $24^{\circ} 00^{\prime} 17^{\prime}$ 'S e $24^{\circ} 05^{\prime} 00^{\prime \prime} \mathrm{S}$ e $46^{\circ} 24^{\prime} 45^{\prime \prime} \mathrm{W}$ e $46^{\circ} 35^{\prime} 31^{\prime}$ 'W. Ao Oeste limita-se com o município de Mongaguá, ao Norte e ao Leste com o município de São Vicente e ao Sul com o Oceano Atlântico. Sua área territorial de $145 \mathrm{~km}^{2}$ corresponde a $6,1 \%$ do total da Região Metropolitana da Baixada Santista. Na figura 1 tem-se a localização da área de estudo.

Figura 1: Localização do município de Praia Grande na Região Metropolitana da Baixada Santista, Estado de São Paulo

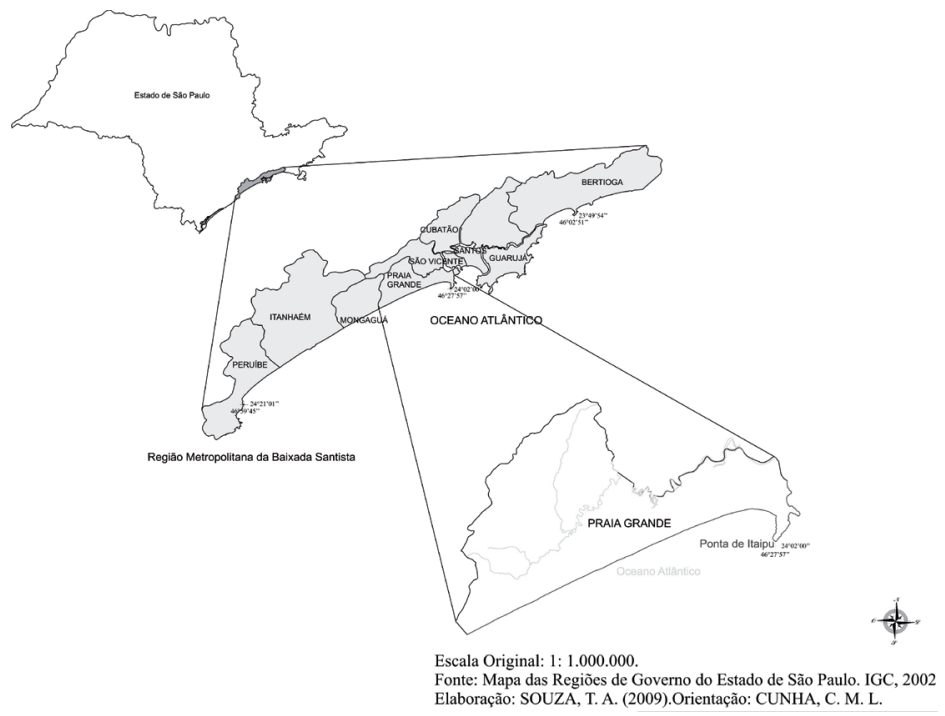

Soc. \& Nat., Uberlândia, ano 24 n. 2, 303-318, mai/ago. 2012 
De acordo com a classificação climática de Monteiro (1973), o município localiza-se numa região do litoral paulista de clima úmido, controlado por massas tropicais e polares. Afonso (2006) ressalta que a umidade relativa do ar é normalmente superior a $80 \%$ devido à elevada evaporação e à barreira formada pela Serra do Mar.

As condições climáticas, aliadas aos aspectos litológicos e pedológicos influenciam no crescimento de três formações vegetais importantes e distintas no município: a Mata Atlântica, presente nas encostas íngremes da Serra do Mar e no Maciço Isolado, conser- vada pela presença de duas Unidades de Conservação: o Parque Estadual Serra do Mar (Decreto Estadual n ${ }^{\circ}$ 10.251, de 30/08/1977) e o Parque Estadual Xixová-Japuí (Decreto Estadual no 37.536, de 27/09/1993).

A mata de restinga se estende sobre o solo arenoso da Planície Quaternária ou Costeira; e os manguezais sobre o solo lodoso da planície flúvio-marinha do rio Piaçabuçu. A distribuição dos tipos de vegetação no município pode ser observada na Figura 2, referente à Carta de Uso da Terra do Município de Praia Grande, ano de 2000.

Figura 2: Carta de Uso da Terra do Município de Praia Grande (SP), ano de 2000.

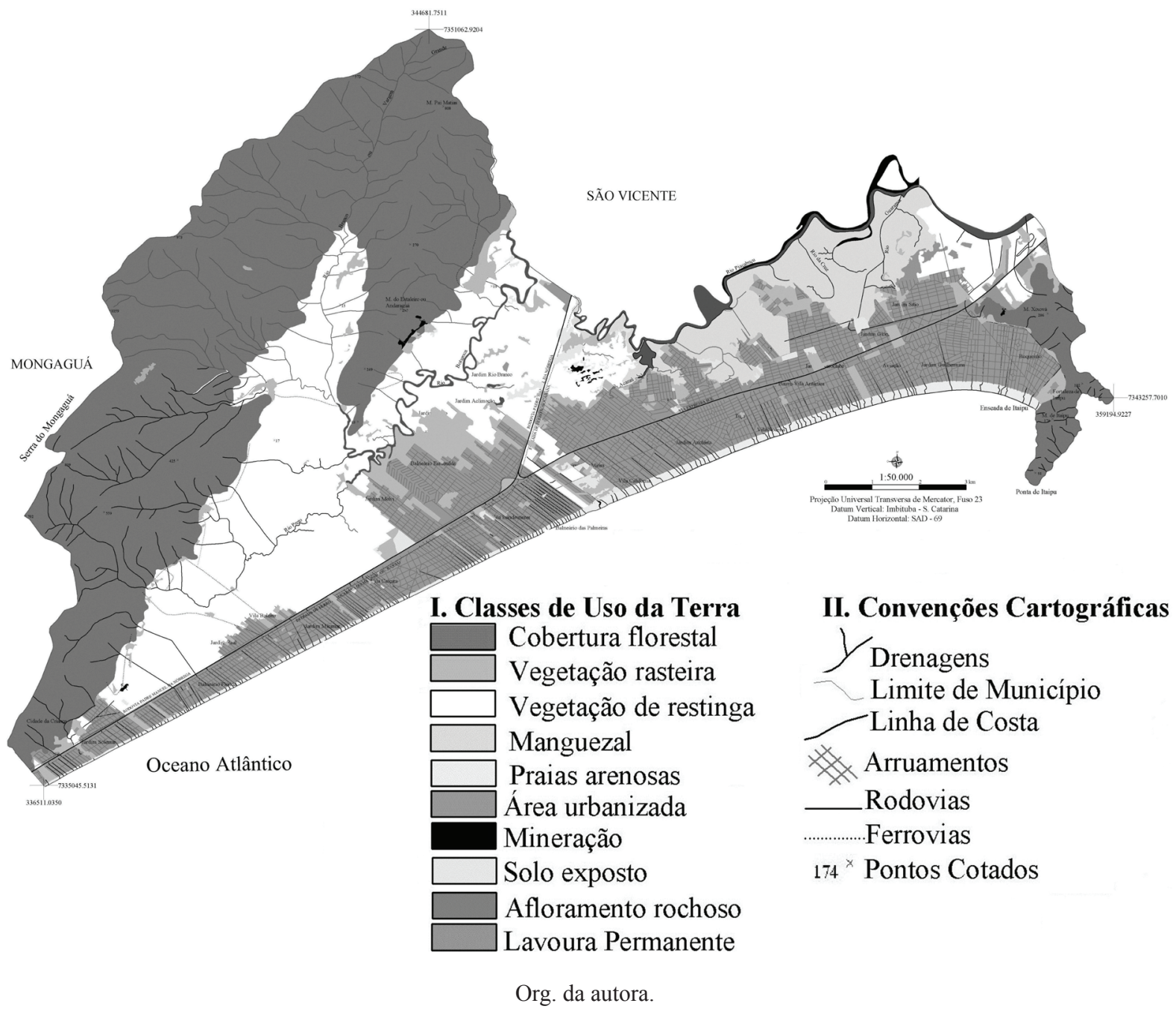


Os tipos de vegetação presentes na área de estudo são influenciados por diversos fatores, incluindo entre eles, os tipos de solo. Conforme Oliveira et. al. (1999), três tipos principais de solos ocorrem com maior frequência no município de Praia Grande, a saber: Gleissolos Sálicos, Espodossolos Ferrocárbicos e Cambissolos Háplicos. A distribuição espacial dos tipos de solos predominantes está representada na Figura 3.

As condições geomorfológicas da região impedem a formação de rios extensos (AFONSO, 2006). A rede fluvial é composta por pequenos rios que nascem na Serra do Mar, passam pela Planície Quaternária e deságuam no Oceano Atlântico. Nas áreas serranas, a forte declividade do terreno provoca características torrenciais nos altos e médios cursos dos rios. Quando chegam à planície, os rios sofrem diminuição da velocidade em razão da declividade suave, o que provoca o processo de deposição de sedimentos.

As características geomorfológicas e geológicas da região, que influenciam diversos fatores físicos da área de estudo, como a hidrografia, estão ligadas à origem e evolução da Serra do Mar e à formação da planície sedimentar Quaternária.

Figura 3: Carta de Solos do Município de Praia Grande (SP)

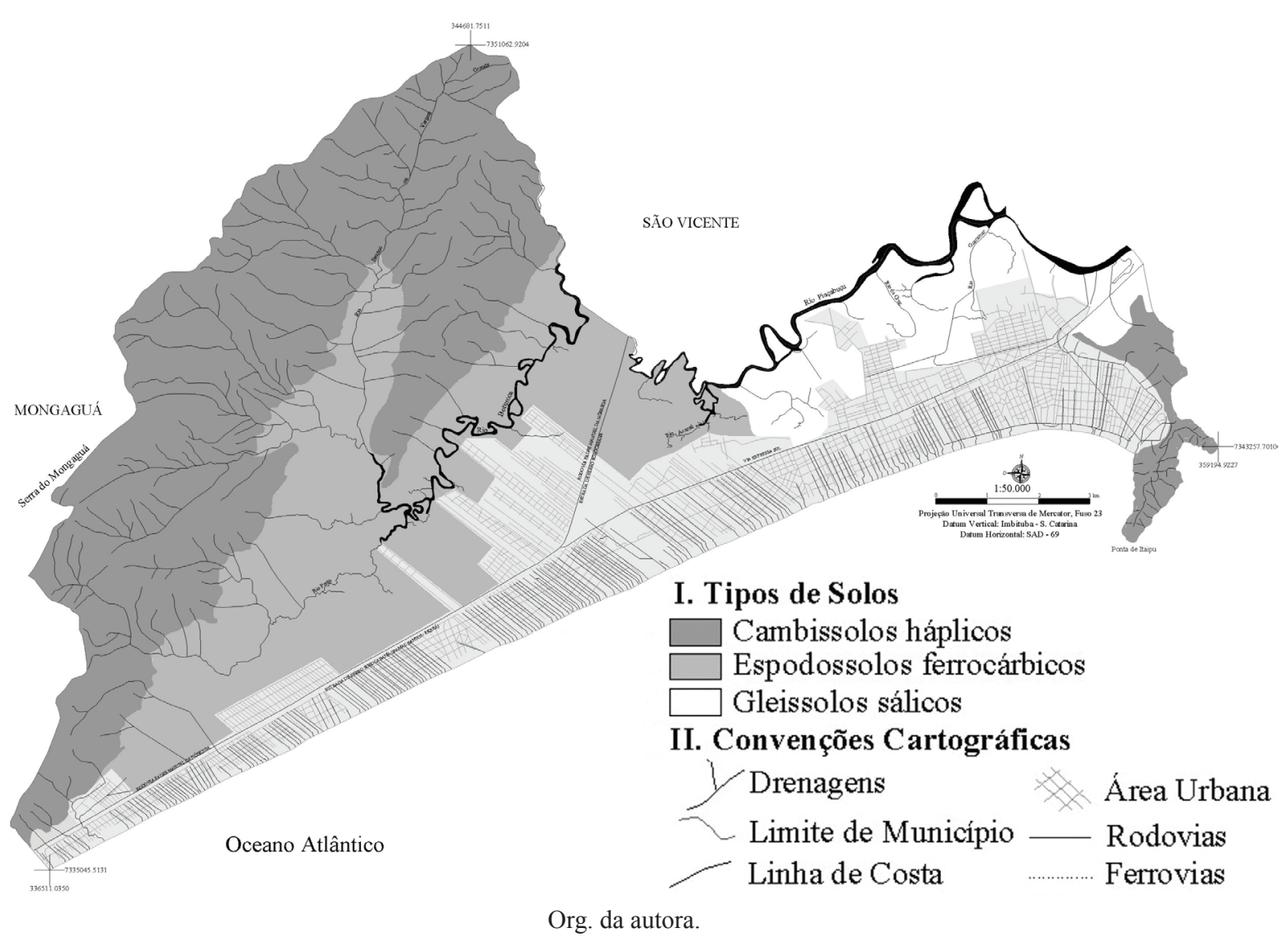

Soc. \& Nat., Uberlândia, ano 24 n. 2, 303-318, mai/ago. 2012 
O contexto geológico regional é marcado pela presença de rochas cristalinas formadas durante o Pré-Cambriano, que compõem a Serra do Mar, e por sedimentos recentes datados do Cenozóico, que se localizam na Planície Quaternária (Figura 4).

Figura 4: Carta Geológica do Município de Praia Grande (SP).

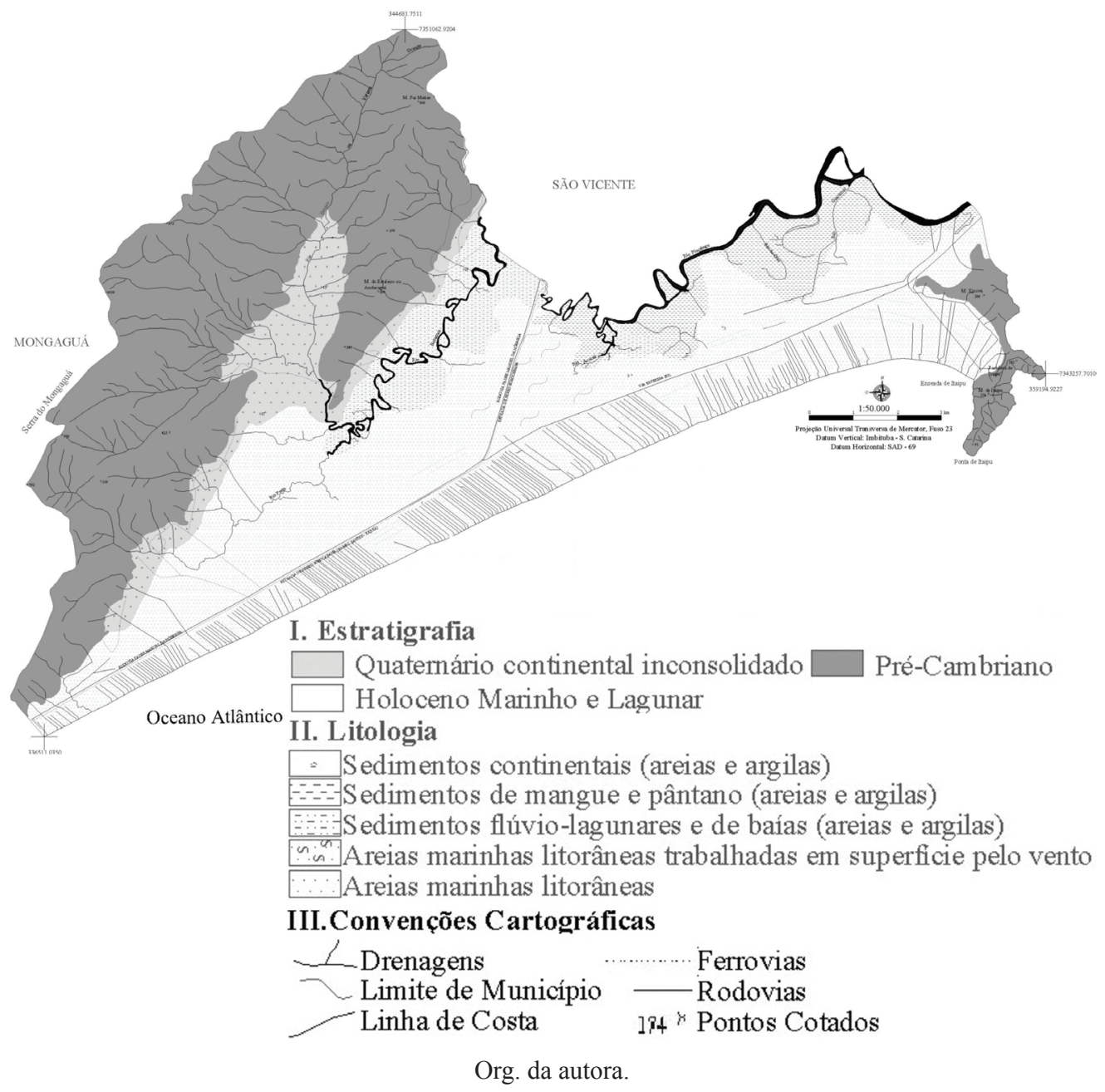

O embasamento cristalino é composto por rochas formadas durante o Arqueano (IPT, 1981a), constituindo a unidade Complexo Costeiro, de grande heterogeneidade, com predomínio de rochas migmatíticas. Podem aparecer xistos, gnaisses, e rochas metamórficas invadidas por magmas graníticos (RODRIGUES, 1965). Ocorrem ainda quartzitos, filitos, rochas carbonáticas e diques de diabásio (SANTOS, 2004).

A Planície Costeira é formada por sedimentos datados do Período Quaternário. Através da análise dos dados de Suguio e Martin (1978), verifica-se que

há um predomínio de areias marinhas litorâneas na Planície Quaternária, com ocorrência de areias marinhas litorâneas trabalhadas em superfície pelo vento e presença de antigas linhas de restinga. No entorno do rio Piaçabuçu ocorrem sedimentos de mangue e de pântano, compostos por areias e argilas. Já nas proximidades do rio Boturoca aparecem sedimentos flúvio-lagunares e de baías, formados por areias e argilas. As rampas coluviais constituem-se de sedimentos continentais consolidados, constituídos por areias e argilas, com estratigrafia do Quaternário Continental. Com relação ao relevo da área de estudo, 
verificam-se duas singularidades: a excessiva inclinação das escarpas, na forma de "pinças de caranguejo" (ALMEIDA, 1953, citado por AB'SABER, 1955) e a Planície Quaternária, de relevo plano (RODRIGUES, 1965).

A Serra do Mar é constituída por rochas resistentes, fator que determina setores de altas decli- vidades. Há um predomínio de vertentes convexas, promovendo a dispersão os fluxos do escoamento pluvial. As vertentes côncavas localizam-se em áreas de maior suscetibilidade litológica, concentrando os fluxos do escoamento pluvial (Figura 5).

Figura 5: Carta Geomorfológica do Município de Praia Grande (SP).
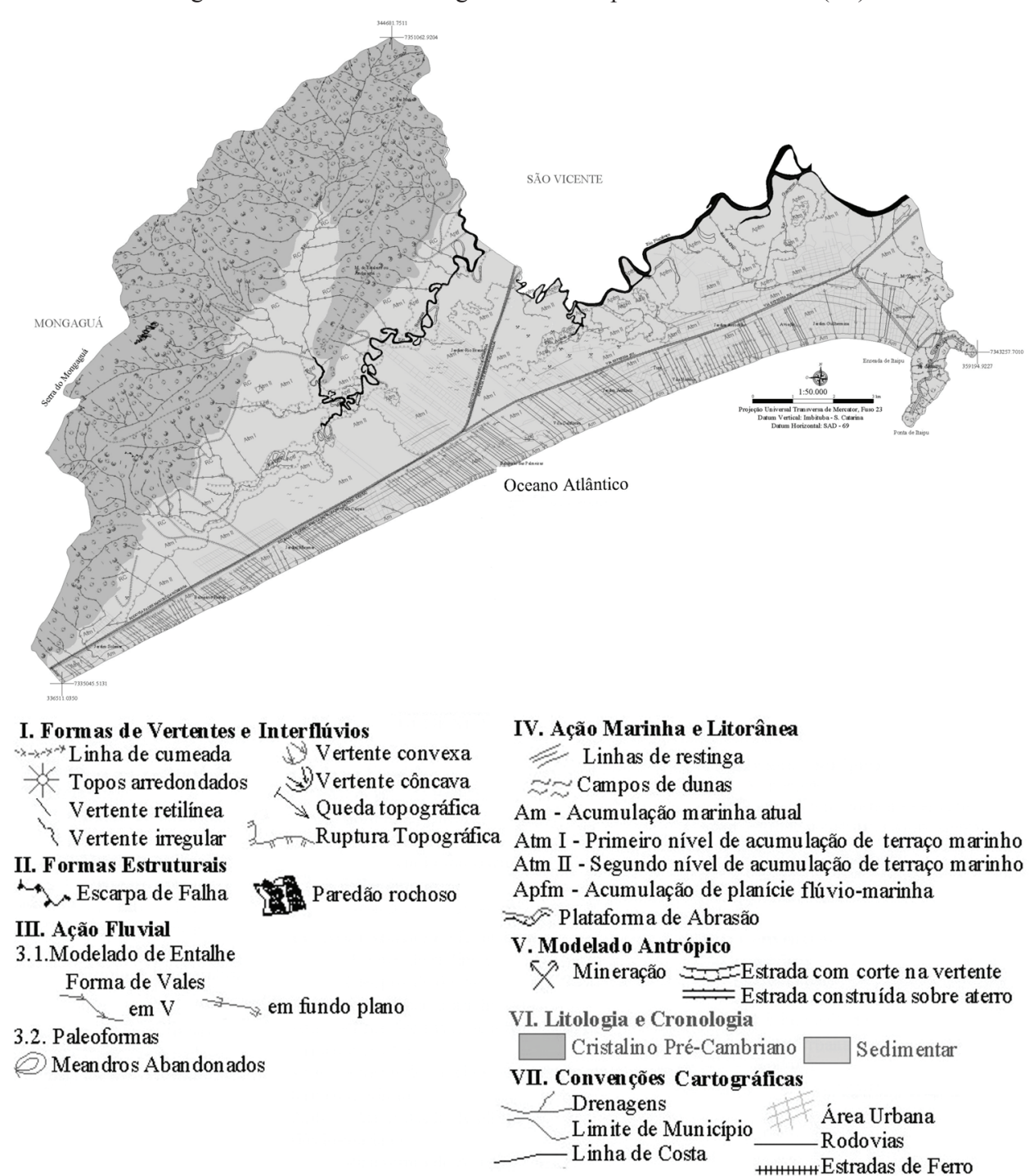

Org. da autora. 
$\mathrm{O}$ maciço cristalino onde se encontram os Morros Xixová e Itaipu apresenta vales em V esculpidos em setores de menor resistência litológica, onde possivelmente ocorreram rupturas derivadas da ação tectônica regional. Vertentes retilíneas aparecem com freqüência neste setor. No contato direto entre rocha e oceano, formou-se uma plataforma de abrasão. As linhas de cumeada são abruptas, bem demarcadas.

A cartografia geomorfológica dos morros do Estaleiro e Pai Matias revela linhas de divisores de águas em crista, que direcionam as drenagens para o rio Piaçabucu, a leste, e para o rio Vargem Grande, a oeste. Ocorre a presença de topos arredondados isolados e vales em V. Vertentes retilíneas e côncavas predominam nesta zona.

Na Serra do Mongaguá registram-se topos arredondados, escarpas de linha de falha, afloramento rochoso e linhas de cumeada abruptas de grandes extensões. Concavidades nas vertentes predominam nesta área e vertentes retilíneas são encontradas com grande frequência.

No setor de Planície Quaternária foram identificadas áreas de sedimentação recente, a saber:

- Acumulação Marinha (Am) formada por sedimentos predominantemente arenosos depositados por ação da deriva litorânea, marés e ondas. As áreas de Acumulação Marinha (Am) apresentam interesse turístico ao município, já que abrigam as praias de uso coletivo.

- Acumulação de Terraços Marinhos em dois níveis (Atm I e Atm II), situada acima do nível do mar e composta por sedimentos arenosos.

As áreas de acumulação de terraço marinho (Atm I e Atm II) apresentam forma plana, com leve inclinação para o mar e ruptura de declive em relação à acumulação marinha atual.

O primeiro nível de terraço (Atm I) está em contato com a acumulação de planície e terraço fluvial dos rios Preto e Boturoca, com a planície flúvio-marinha do rio Piaçabuçu e em contato com a acumulação marinha. Neste nível de terraço aparecem cordões litorâneos, que hoje se encontram totalmente urbanizados (Figura 5).

Campos de dunas são encontrados nos dois níveis de terraços, sendo que alguns destes campos estão arrasados pela urbanização, restando somente vestígios do retrabalhamento das areias pelo vento.

A transição entre Atm II e Atm I é marcada pela presença de uma ruptura topográfica, ou seja, há uma mudança nítida de um nível de terraço para outro. A presença da rodovia Padre Manuel da Nóbrega na passagem do Atm II para o Atm I dificulta precisar os limites entre estes devido a sua construção ser realizada sobre aterros que distorcem a topografia, como pode ser verificado na Carta Geomorfológica.

-Acumulação de Planície e Terraço Fluvial (Aptf), formada por sedimentos transportados pela ação das águas fluviais. As áreas de acumulação de planície e terraço fluvial (Apft) ocorrem com maior intensidade no interior do continente, margeando os rios Branco, Preto e Boturoca.

$\mathrm{Na}$ Aptf são registrados meandros abandonados, que correspondem ao antigo curso dos rios Preto e Boturoca.

-Acumulação de Planície Flúvio-Marinha (Apfm), caracterizadas como terrenos baixos com lamas de depósitos recentes, sujeitos as inundações das marés. A planície flúvio-marinha (Apfm) ocorre no entorno do rio Piaçabuçu.

$\mathrm{Na}$ transição entre cristalino e sedimentar estão as Rampas de Colúvio (Rc), constituídas de material transportado da Serra do Mar pela força da gravidade, com o auxilio do escoamento superficial.

A partir das características descritas acima, constata-se que o município apresenta dois setores distintos: Sistema Serrano e Planície Quaternária ou Costeira. Apesar da diversidade de processos ocorrentes, deve-se considerar que estes sistemas estão inter-relacionados através da troca de energia e matéria de forma contínua.

\section{MÉTODO E TÉCNICAS}

\section{Método}

A integração dos dados obtidos neste trabalho baseia-se nos pressupostos da Teoria Geral dos Sistemas. O princípio básico desta Teoria refere-se à integração de um conjunto de elementos/atributos que se encontram inter-relacionados, e que geram um todo complexo, único, organizado (CHRISTOFOLETTI, 1971; CHRISTOFOLETTI, 1999, MATTOS; PEREZ 
FILHO, 2004). As relações entre os elementos de um sistema dependem dos fluxos de entrada e saída de matéria e energia. A abordagem sistêmica tem sido amplamente utilizada por profissionais ligados ao estudo das questões ambientais e seu emprego tem sido analisado como um dos mais produtivos no que se refere aos resultados obtidos.

Conforme Christofoletti (1979), à Geografia interessa a análise de sistemas através dos critérios de funcionalidade e de complexidade estrutural, pois estes admitem que as organizações espaciais sejam melhor estudadas.

De acordo com o critério da funcionalidade, o município de Praia Grande é classificado como um sistema aberto, no qual ao modificar um de seus elementos, todo o sistema sofrerá alteração. Neste contexto também se enquadra a ação antrópica, que pode se processar livremente, já que o sistema aberto recebe energia e matéria de qualquer agente externo que possa agir sobre ele.

Conforme o critério da complexidade estrutural, a análise se baseia nos princípios relacionados ao sistema controlado, no qual há intervenção antrópica no fluxo de matéria e energia, modificando os processos e as formas.

\section{Técnicas}

Para a elaboração das cartas que compõem esta pesquisa foram utilizadas diversas fontes de dados como cartas topográficas, fotografias aéreas no formato analógico e digital, dados geológicos e pedológicos compilados da bibliografia, os quais foram sistematizados de acordo com as técnicas a seguir descritas.

A Carta Geológica (Figura 4) foi elaborada a partir da compilação de dados das Folhas Geológicas Santos e Itanhaém (SUGUIO; MARTIN, 1978), na escala 1:100.000 e posteriormente adaptadas no ambiente do software Auto CAD Map 2004 à escala 1:50.000.

A Carta de Solos (Figura 3) foi organizada a partir da digitalização, via scanner, do Mapa Pedológico do Estado de São Paulo elaborado por Oliveira et. al. (1999) e em seguida adaptado à escala 1:50.000 através do software AutoCAD Map 2004.
A Carta Clinográfica foi elaborada com base na metodologia do ábaco analógico proposta por De Biasi (1992), com a colaboração das propostas de Sanchez (1993) a respeito do ábaco suplementar, e Simon e Cunha (2009), com a semi-automatização da metodologia de De Biasi (1992) aplicada ao ambiente digital do software Auto CAD Map.

As Cartas de Dissecação Horizontal e de Dissecação Vertical foram confeccionadas com base na metodologia de Spirodonov (1981). Para a elaboração destas cartas foram utilizadas técnicas semi-automáticas desenvolvidas por Zacharias (2001) no ambiente digital do software AutoCAD Map.

A Carta Geomorfológica (Figura 5) foi organizada a partir da interpretação de fotografias aéreas na escala aproximada de 1:25.000, datadas do ano de 1962, com o auxílio de estereoscópio de bolso. Para a montagem da legenda da carta geomorfológica, utilizou-se como base a proposta de Tricart (1965), incluindo nesta algumas simbologias apresentadas por Verstappen e Zuidam (1975).

A Carta de Uso da Terra do Município de Praia Grande foi elaborada a partir de um mosaico semi-ajustado de fotográfias aéreas digitais (SÃO PAULO, 2000). Estas fotografias foram georeferenciadas e interpretadas visualmente no software Auto CAD Map 2004. As classes de uso foram definidas com base no Manual Técnico de Uso da Terra (IBGE, 2006), com adaptações referentes à presença de afloramentos rochosos, manchas de solo exposto e praias arenosas.

\section{RESULTADOS}

O Município de Praia Grande caracteriza-se pela presença de dois grandes setores: um dominado pelo embasamento cristalino antigo, com escarpas excessivamente inclinadas, conhecido regionalmente como Serra do Mar; e outro denominado de Planície Costeira ou Quaternária, formada por sedimentos recentes pouco consolidados, de relevo plano. Estes setores apresentam características diferenciadas e os processos atuantes em cada setor agem de maneiras distintas.

Na Baixada Santista, conforme Amorim e Oliveira (2009), a Serra do Mar acompanha a costa e forma um grande anfiteatro que abriga a planície

Soc. \& Nat., Uberlândia, ano 24 n. 2, 303-318, mai/ago. 2012 
sedimentar. Os autores destacam que a disposição assumida pelo relevo influencia nas características climáticas e vegetacionais, nos processos de erosão e de deposição de materiais, nos processos pedogenéticos e no tipo de escoamento (fluvial e pluvial).

Em Praia Grande, o embasamento cristalino entra em contato direto com o mar na parte leste, na Ponta de Itaipu. No restante do município, as escarpas da Serra do Mar se distanciam das águas oceânicas, criando condições para a sedimentação de uma extensa planície retilínea.

No setor da Serra do Mar, formado por rochas datadas do Pré-Cambriano (Figura 4) a heterogeneidade da litologia interfere nos processos erosivos atuantes, nas formas de relevo, nas declividades e na dissecação do relevo.

A vegetação de Mata Atlântica sustenta-se sobre Cambissolos Háplicos, caracterizados pela pequena profundidade (1,5 metros) (OLIVEIRA,
1999). Segundo São Paulo (1997), para a estabilidade das vertentes é necessária a manutenção da cobertura vegetal, pois a presença desta amortece a ação direta dos agentes intempéricos, principalmente as águas das chuvas, minimizando processos erosivos que podem resultar em escorregamentos.

Os solos na área serrana formam-se em vertentes de declividades acentuadas, nas quais predominam as classes entre $20-30 \%$ e acima de $30 \%$ (Figura 6). As maiores declividades geralmente ocorrem nas médias vertentes das escarpas, nas quais ocorrem abruptas rupturas de declive. A inclinação das vertentes intensifica a ação do escoamento superficial, o que pode dinamizar os processos de movimentos de massa devido à ação da gravidade.

As altas declividades encontram-se principalmente nos setores de grande resistência das rochas.

Figura 6: Carta Clinográfica do Município de Praia Grande (SP)

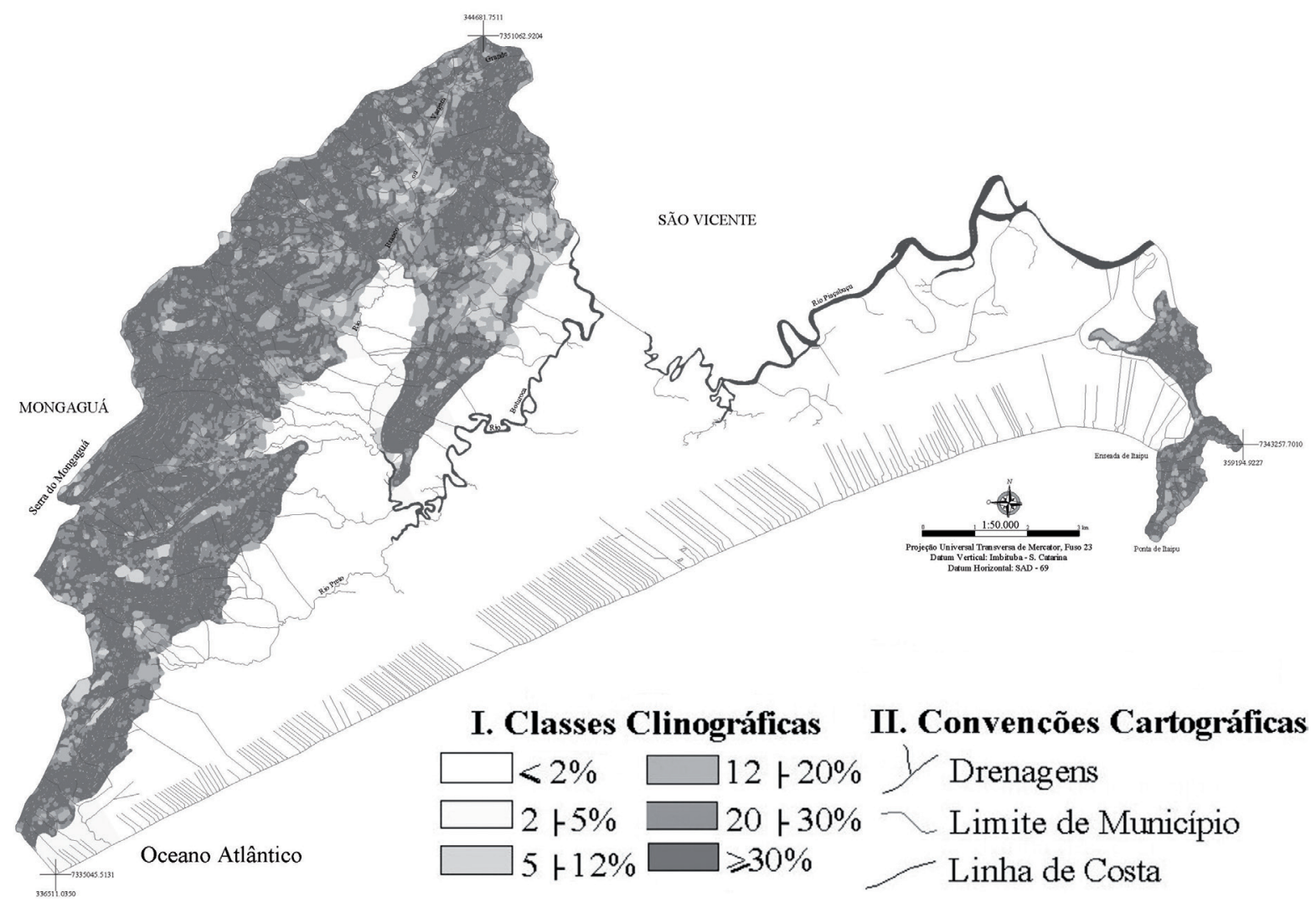


Nas áreas serranas as classes de dissecação vertical variam de 20 a 40 metros até maior e/ou igual a 100 metros (Figura 7), onde a ruptibilidade das litologias cristalinas se manifesta através de fraturamentos e falhamentos nos quais se encaixam as drenagens. Assim, o desnível altimétrico entre os topos e tais drenagens, muitas vezes, é significativo.

Figura 7: Carta de Dissecação Vertical do Município de Praia Grande (SP)

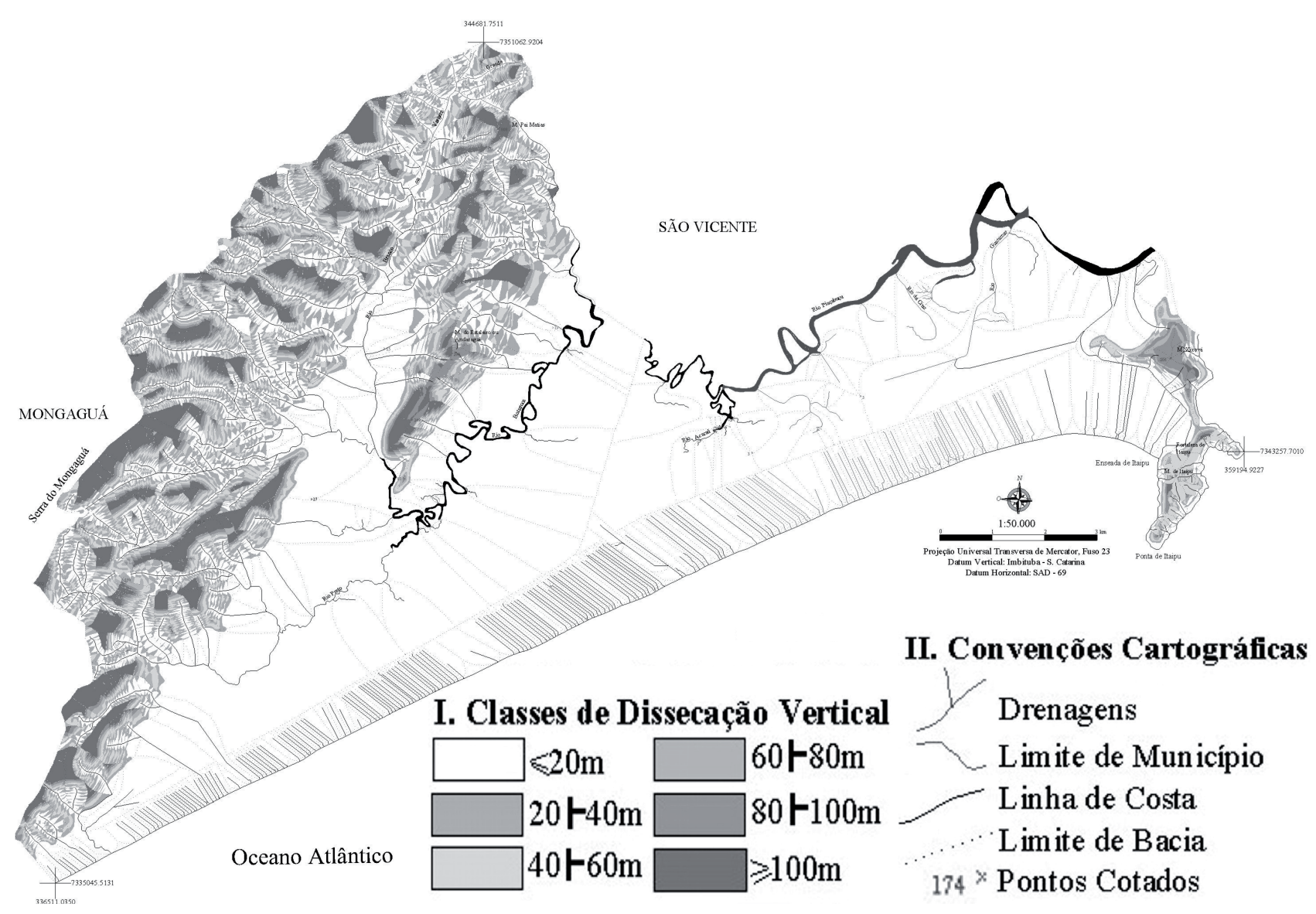

Org. das autoras.

A fim de melhor interpretação dos dados referentes à área de estudo, analisou-se o setor cristalino através de sua subdivisão em unidades menores: Morros de Itaipu e Xixová, Morro do Estaleiro ou Andaraguá, Morro do Pai Matias e Serra do Mongaguá.

Os Morros de Itaipu e Xixová se localizam no único maciço cristalino isolado presente no município. Este maciço cristalino provavelmente foi separado da Serra do Mar por eventos tectônicos e de sedimentação ocasionados pelas variações do nível do mar, apre- sentando vales em $\mathrm{V}$ esculpidos em setores de menor resistência litológica, onde possivelmente ocorreram rupturas derivadas da ação tectônica regional. Neste setor são encontradas vertentes retilíneas. As linhas de cumeada são bem demarcadas e abruptas. No contato direto entre rocha e oceano formou-se uma plataforma de abrasão (Figura 5).

Outra característica do relevo dos Morros de Itaipu e Xixová se refere aos valores de dissecação horizontal (Figura 8). Os valores mais altos (menores

Soc. \& Nat., Uberlândia, ano 24 n. 2, 303-318, mai/ago. 2012 
e/ou iguais a 50 metros), ou seja, as menores distâncias entre talvegue e linha de cumeada são encontradas nas confluências das drenagens. Sato e Cunha (2007) destacam que este fato demonstra que o potencial erosivo se acumula ao longo do canal fluvial e tem seu ápice no setor de confluência. Já as classes de dissecação horizontal de valores médios, de até 400 metros, aparecem neste maciço isolado nas áreas de nascentes. Assim, o referido maciço apresenta variadas características em termos de dissecação horizontal.

Figura 8: Carta de Dissecação Horizontal do Município de Praia Grande (SP)

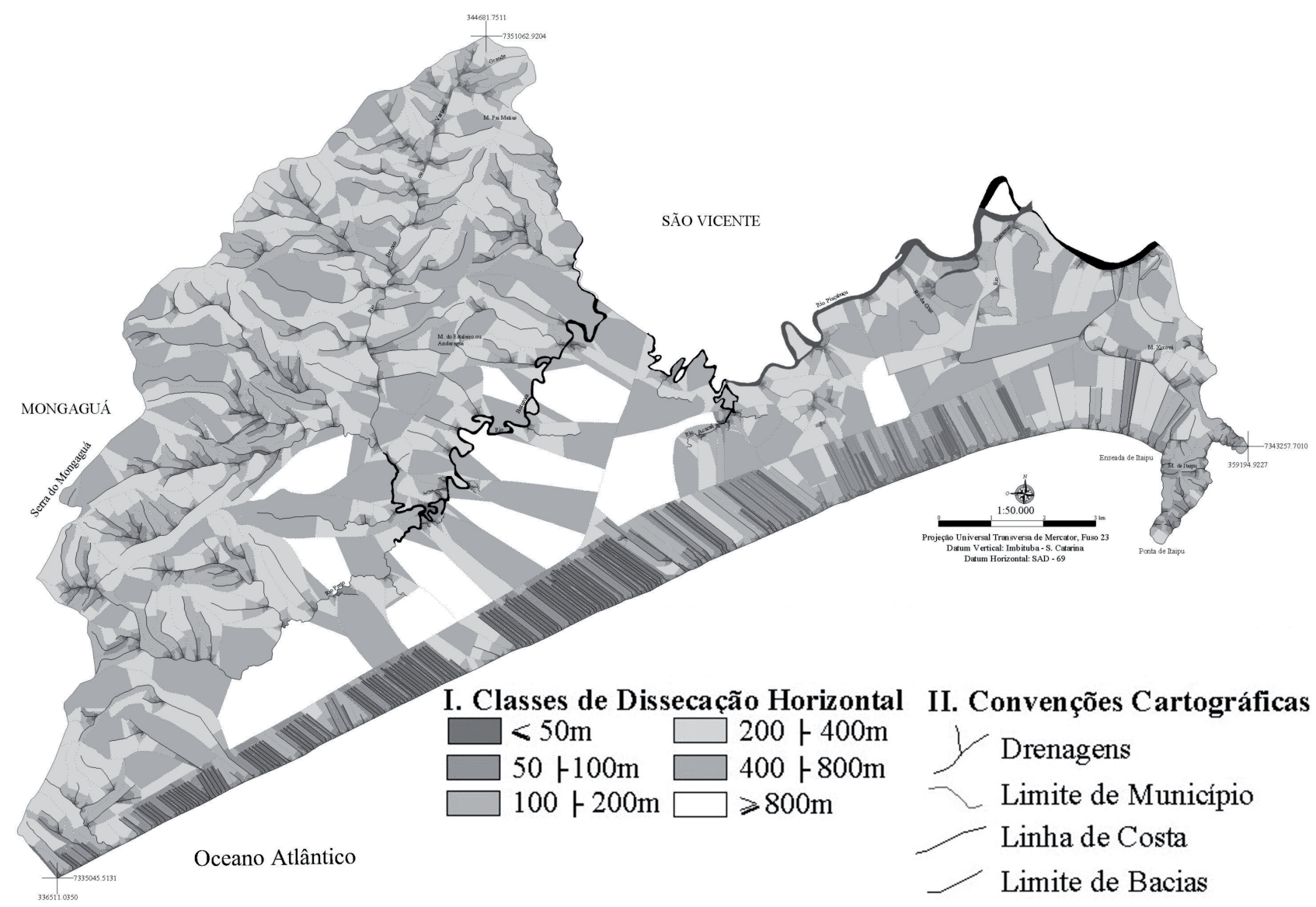

Org. das autoras.

Com relação às classes de dissecação vertical, no Morro de Itaipu há domínio de valores menores e/ ou iguais a 20 metros e de 20 a 40 metros (Figura 7). No Morro Xixová, as classes chegam a maior e/ou igual a 100 metros, o que demonstra uma considerável resistência litológica, influenciando na altitude relativa entre talvegue e linha de cumeada. As drenagens acompanham os falhamentos presentes nas rochas, $o$ que também explica o grande entalhamento.

Segundo Sato e Cunha (2007), através da carta de dissecação vertical,é possível avaliar a ação gravitacional a qual é uma componente importante em razão de sua estreita relação com as atividades erosivas, já que o desnível altimétrico entre o limite da bacia e o talvegue pode dinamizar a pela remobilização de material.

Já a análise dos setores do Morro do Estaleiro ou Andaraguá e do Morro do Pai Matias revela que nestas unidades, a dissecação vertical é mais profunda, atingindo a classe maior e/ou igual a $100 \mathrm{~m}$. As classes acima de 100 metros mostram que as nascentes estão altimetricamente distantes da linha divisora de águas, 
seja por ação da resistência litológica ou ainda pela escala de trabalho adotada neste trabalho, que não permite um detalhamento maior da rede de drenagem do município (Figura 7).

Com relação à dissecação horizontal do relevo, no Morro do Estaleiro ou Andaraguá não há uma rede de drenagem densa, e as classes de dissecação horizontal que se manifestam com maior frequência estão entre 200 e 800 metros, ou seja, a linha de cumeada está distante do talvegue, enquanto no Morro Pai Matias, a rede de drenagem é mais densa que no setor anterior e as classes entre 100 e 400 metros são dominantes, sendo esta área potencialmente mais suscetível à ação dos rios sobre o relevo (Figura 8).

As linhas divisoras de águas dos Morros do Pai Matias e do Estaleiro direcionam as drenagens, encaixadas em vales em V, para o rio Piaçabuçu, a leste, e para o rio Vargem Grande, a oeste (Figura 5).

O último setor serrano analisado é a chamada Serra do Mongaguá, que marca o limite entre os municípios de Praia Grande e Mongaguá. Neste setor, há um predomínio de vertentes côncavas, porém também são encontradas com grande freqüência vertentes retilíneas. As drenagens encontram-se encaixadas em rochas menos resistentes à ação das águas e nos planos de falha, formando vales em V. Na Serra do Mongaguá também são encontrados afloramentos rochosos, linhas de cumeadas abruptas e com grandes extensões, escarpas de linha de falha e morros com topos arredondados (Figura 5).

$\mathrm{Na}$ Serra do Mongaguá, a rede de drenagem mostra grande variação em sua distribuição espacial - em alguns pontos a rede é densa e a dissecação horizontal é intensa, com predominância de classes entre 100 e 400 metros e, em outros pontos, a dissecação é baixa, com valores que atingem até 800 metros (Figura 8).

Com relação à dissecação vertical do relevo, há alternância entre áreas de alta dissecação vertical, com valores maiores e/ou iguais a 100 metros e pequenas bacias, onde a dissecação vertical não ultrapassa a classe de 20 a 40 metros (Figura 7).

As restrições ao uso da terra na Serra do Mar se relaciona à presença, a partir da cota de 100 metros, do Parque Estadual Serra do Mar (Decreto Estadual $\mathrm{n}^{\mathrm{o}} 10.251$, de 30/08/1977), que tem como função a preservação permanente dos atributos naturais excepcionais (Decreto Estadual n ${ }^{\circ} 25.341$, de 04/07/1986). Portanto, neste setor do município, o uso da terra é limitado pela legislação ambiental. Além das restrições impostas pela legislação, o acesso à área serrana é dificultado pela existência da vegetação de Mata Atlântica e pela presença de vertentes excessivamente inclinadas.

O morro cristalino isolado também integra uma Unidade de Conservação: o Parque Estadual Xixová-Japuí (Decreto Estadual no 37.536, de 27/09/1991). A legislação ambiental impõe restrições ao uso da terra, sendo uma área destinada à preservação da Mata Atlântica.

A transição da Serra do Mar para a Planície Costeira ocorre de forma abrupta. As altas declividades do setor cristalino contrastam com o aplainamento da área sedimentar (Figura 6). A declividade da Planície Costeira varia entre menor que $2 \%$ e $2+5 \%$ (Figura 6). As altitudes máximas atingem 15 metros, nas proximidades do rio Branco ou Vargem Grande e 19 metros nas proximidades do rio Boturoca. O setor de Planície Costeira é constituído por diferentes áreas de sedimentação recente, a saber:

-Acumulação Marinha (Am), constitui-se essencialmente por sedimentos arenosos. Nesta área ocorre solo do tipo Espodossolo Ferrocárbico, que segundo Oliveira (1999) se localiza nas áreas de atividades de uso da terra relacionada ao turismo, com intensa exploração antrópica.

-Acumulação de Terraços Marinhos (Atm I e Atm II), onde predomina o solo do tipo Espodossolo Ferrocárbico. Nesta área ocorrem diversos tipos de uso da terra, apesar de suas características naturais implicarem em restrições de uso. As áreas de restinga são compatíveis com as propriedades naturais dos terraços marinhos. Nas proximidades com a SP-055 (Rodovia Padre Manuel da Nóbrega) e no contato com $\mathrm{a}$ área urbana aparecem manchas de vegetação rasteira e solo exposto. Há ainda antigas áreas de mineração e atividade agrícola.

-Acumulação de Planície e Terraço Fluvial (Aptf), que assim como nos setores anteriores, ocorre solo do tipo Espodossolo Ferrocárbico. Nas proximidades do rio Preto, há predominância de sedimentos marinhos, enquanto nos arredores do rio Boturoca

Soc. \& Nat., Uberlândia, ano 24 n. 2, 303-318, mai/ago. 2012 
predominam sedimentos flúvio-lagunares e de baías (areias e argilas). Esta unidade é ocupada predominantemente por vegetação de restinga. Nas proximidades com a área urbana, a vegetação original foi substituída por vegetação rasteira.

-Acumulação de Planície Flúvio-Marinha (Apfm), caracterizada no entorno do rio Piaçabuçu pela ocorrência de sedimentos de mangue e de pântano (areias e argilas). De acordo com Oliveira et. al. (1999) ocorrem Gleissolos Sálicos, que são solos típicos de regiões litorâneas que se localizam em áreas de saturação de água. A vegetação de mangue domina este setor, porém alguns trechos sofrem com o avanço da urbanização, além da presença de vegetação rasteira.

$\mathrm{Na}$ transição entre cristalino e sedimentar estão as Rampas de Colúvio (Rc), que conforme Suguio e Martin (1978) são compostas por sedimentos continentais (areias e argilas). Neste setor, o uso da terra relaciona-se à heterogeneidade do material componente das rampas coluviais, devendo ser destinado apenas para a vegetação de restinga. Ocorrem também manchas de vegetação rasteira.

De maneira geral, a Planície Costeira em sua totalidade é caracterizada pela presença de vales de fundo plano (Figura 5), localizados em áreas de declividades pouco acentuadas, que variam de 2 a $5 \%$, chegando a $20 \%$ no sopé da Serra do Mar, nas áreas transicionais das rampas de colúvios (Figura 6).

Na Planície Costeira de Praia Grande, zona fortemente influenciada pela ação humana e seu processo de urbanização, predominam valores de dissecação horizontal menor e/ou igual a 50 metros e de 50 a 100 metros. Este fato indica que na planície, em direção ao Oceano Atlântico, há um alto grau de trabalho da drenagem fluvial e demonstra a elevada densidade de drenagem neste setor do município. Estes canais existentes na planície costeira, como foi exposto por Souza e Cunha (2009), mesmo sendo transformados pela atuação do homem, não podem ser ignorados na análise morfométrica, pois influenciam no processo de dissecação da planície marinha, já que há um fluxo constante de água em direção ao mar que provoca processos erosivos na linha de costa. Ainda no setor da planície costeira, em área em que as drenagens se dirigem para os rios Preto, Boturoca e Piaçabuçu, predominam valores de dissecação horizontal que variam de 200 até acima de 800 metros, ou seja, de média a baixa. Este fato se deve à baixa densidade de drenagem deste setor (Figura 8).

Já a carta de dissecação vertical mostra que na planície costeira há predominância absoluta da classe menor e/ou igual a 20 metros, devido ao pequeno desnível altimétrico existente entre esses terrenos e a linha de costa.

\section{CONSIDERAÇÕES FINAIS}

A Serra do Mar e a Planície Quaternária, apesar de serem sistemas com características diferenciadas nos aspectos pedológicos, geológicos, geomorfológicos, morfométricos, vegetacionais e de uso da terra, estabelecem relações de vizinhança, e, portanto, estão interligados através dos processos de circulação de matéria e energia. A energia e matéria provenientes do Sistema Serrano, através dos processos gravitacionais e do escoamento fluvial e pluvial são transmitidas à Planície Quaternária.

Com relação às características geológicas, verifica-se que a Serra do Mar é formada por rochas cristalinas Pré-Cambrianas, portanto antigas e resistentes aos processos de intemperismo, enquanto a Planície Costeira é composta por sedimentos recentes e inconsolidados, que sofrem intensa modificação pela urbanização.

Os aspectos pedológicos revelam que na Serra do Mar predominam solos pouco profundos e pouco desenvolvidos. Na Planície Costeira, os solos são arenosos, com lençol freático raso e com alta porosidade.

A análise da carta geomorfológica permite afirmar que a Serra do Mar caracteriza-se como uma área de altas declividades, com presença de afloramentos rochosos, escarpas de falha, linhas de cumeada abruptas e vales encaixados nas linhas de fraqueza das litologias. Na zona da Planície Costeira ocorrem formas de relevo como campos de dunas, cordões litorâneos e vales de fundo plano sujeitos a inundações em razão da baixa declividade do terreno.

No setor serrano, o processo de dissecação do relevo ocorre por ações naturais, já que esta área não é ocupada pelo processo de urbanização. Já na Planície Costeira, constata-se uma forte influência da ação antrópica, alterando os processos de disseca- 
ção do relevo. Com relação à dissecação horizontal, verifica-se que o setor urbanizado da planície costeira é o que sofre o maior potencial erosivo, sobretudo pelas intervenções humanas nesta área.

Com relação à dissecação vertical, verifica-se que na Planície Costeira o trabalho da ação gravitacional é baixo, em razão do pequeno desnível altimétrico entre os limites das bacias e o nível de base local, enquanto nas áreas serranas a força da gravidade age com maior intensidade, em razão do maior desnível altimétrico existente no interior das bacias hidrográficas.

Sobre o uso da terra, na Serra do Mar e no Morro Isolado este é restrito pela legislação ambiental, pois estas áreas são pertencentes aos Parques Estaduais Serra do Mar e Xixová-Japuí. As características intrínsecas destas áreas, como altas declividades e densa vegetação de Mata Atlântica dificultam o acesso a esta área. Uma possível ocupação do setor serrano poderia resultar na aceleração de processos gravitacionais, como deslizamentos e corridas de lama, além da retirada da cobertura vegetal original.

É na planície que intervenções antrópicas atuam com maior intensidade, sobretudo pelos impactos causados pela urbanização, que ocupou espaços antes cobertos por vegetação de restinga. Como forma de preservação de espécies deste tipo de vegetação, aponta-se a necessidade de criação de parques.

A urbanização consolidou-se nos terrenos próximos à orla, e atualmente a expansão urbana direciona-se para os fundos de vales dos rios Boturoca e Preto e à planície flúvio-marinha ocupada pelos manguezais que margeiam o rio Piaçabuçu. Para os manguezais, atenta-se para a necessidade de maior fiscalização do Parque do Piaçabuçu por parte da Prefeitura Municipal.

Nas rampas de colúvio, a urbanização deve ser evitada, pois estas áreas recebem materiais com diferentes granulometrias, o que intensifica a instabilidade dos terrenos. A proximidade da área urbana com as rampas de colúvio exige atenção especial por parte dos órgãos públicos, pois no período das chuvas há um maior risco de deslizamento de terras.

As praias também não são passíveis de serem urbanizadas, pois há uma constante remobilização de sedimentos pela ação das ondas e marés. Uma possível urbanização destas áreas também poderia resultar em prejuízos materiais caso houvesse uma forte ressaca ou erosão marinha.

\section{AGRADECIMENTOS}

À Fundação de Amparo à Pesquisa do Estado de São Paulo - FAPESP - pelo financiamento desta pesquisa (Processo no 2009/02483-3).

\section{REFERÊNCIAS}

AB'SABER, A. N. Contribuição à geomorfologia do litoral paulista. Revista Brasileira de Geografia, São Paulo, n.1, p.3-48, jan.-mar. 1955.

AFONSO, C. M. A paisagem da Baixada Santista: urbanização, transformação e conservação. São Paulo: Editora da Universidade de São Paulo: FAPESP, 2006.

ALMEIDA, F. F. M. Fundamentos Geológicos do Relevo Paulista. São Paulo: Universidade do Estado de São Paulo, 1974 (IGEOP - USP Série Teses e Monografias, n.14).

AMORIM, R. R.; OLIVEIRA, R. C. O estudo das unidades de relevo em municípios da faixa costeira brasileira: o exemplo do município de São Vicente SP. Caminhos de Geografia, Uberlândia, v.10, n.10, p. 163-183, jun. 2009.

CHRISTOFOLETTI, A. A Teoria dos Sistemas. Boletim de Geografia Teorética, Rio Claro, v.1, n.2, p. 43-60. 1971.

CHRISTOFOLETTI, A. Análise de Sistemas em Geografia: Introdução. São Paulo: Hucitec, 1979.

CHRISTOFOLETTI, A. Modelagem de Sistemas Ambientais. São Paulo: Edgard Blücher, 1999.

DE BIASI, M. A carta clinográfica: os métodos de representação e sua confecção. Revista do Departamento de Geografia, São Paulo, v.6, p. 45-53, 1992.

Soc. \& Nat., Uberlândia, ano 24 n. 2, 303-318, mai/ago. 2012 
EMPRESA PAULISTA DE PLANEJAMENTO METROPOLITANO S.A - EMPLASA. Plano Metropolitano de Desenvolvimento Integrado. Região Metropolitana da Baixada Santista. 2002. 100p. Disponível em: $<$ http://www.agem.sp.gov.br/pdf/PMDI. pdf $>$. Acesso em: 21 mai. 2008.

INSTITUTO BRASILEIRO DE GEOGRAFIA E ESTATÍSTICA (IBGE). Manual Técnico de Uso da Terra. $2^{\text {a }}$ Edição, Rio de Janeiro: IBGE, 2006.

INSTITUTO DE PESQUISAS TECNOLÓGICAS (IPT). Mapa Geológico do Estado de São Paulo. São Paulo: IPT, 1981a.

INSTITUTO DE PESQUISAS TECNOLÓGICAS (IPT). Mapa Geomorfológico do Estado de São Paulo. São Paulo: IPT, 1981b.

KRONKA, F. J. N. et. al. Inventário florestal da vegetação natural do estado de São Paulo. Instituto Florestal/Secretaria do Meio Ambiente. São Paulo: Imprensa Oficial, 2005.

LACERDA, L. D. Os manguezais do Brasil. In: Vannucci, M. Os manguezais e nós: uma síntese de percepções. São Paulo: Editora da Universidade de São Paulo, 1999. p.185-196.

LAMPARELLI, C. C. (org.). Mapeamento dos ecossistemas costeiros do Estado de São Paulo. São Paulo: Secretaria do Meio Ambiente, CETESB, 1998.

MATTOS, S. H. V. L.; PEREZ FILHO, A. Complexidade e estabilidade em sistemas geomorfológicos: uma introdução ao tema. Revista Brasileira de Geomorfologia, Rio de Janeiro, n 1, p.11-18, 2004.

MONTEIRO, C. A. F. A dinâmica climática e as chuvas no Estado de São Paulo: estudo geográfico sob a forma de Atlas. São Paulo: IG/USP, 1973.

OLIVEIRA, J. B. et. al. Mapa Pedológico do Estado de São Paulo. Campinas: Instituto Agronômico, 1999. 4 mapas. Escala 1:500.000. Acompanha legenda expandida.
OLIVEIRA, J. B. Solos do Estado de São Paulo: descrição das classes registradas no mapa pedológico. In: Boletim Cientifico, n.45, Instituto Agronômico, Campinas, 1999.

RODRIGUES, J. C. As Bases Geológicas. In: Azevedo, A. (org.). A Baixada Santista: aspectos geográficos. Volume I: as bases físicas. São Paulo: Editora da Universidade de São Paulo, 1965. Cap. 1, p.23-48.

ROMARIZ, D. A. Aspectos da vegetação do Brasil. $2^{a}$ Ed. São Paulo: edição da autora, 1996.

SANCHEZ, M. C. A propósito das cartas de declividade. In: Simpósio de Geografia Física Aplicada, 5., 1993, São Paulo. Anais... São Paulo: Faculdade de Filosofia, Letras e Ciências Humanas, p.311-314, 1993.

SANTOS, A. R. A grande barreira da Serra do Mar: da trilha dos Tupiniquins à Rodovia dos Imigrantes. São Paulo: o Nome da Rosa, 2004.

SÃO PAULO (Estado). Secretaria do Meio Ambiente do Estado de São Paulo/ CINIP/ IF. Mosaico semi-ajustado. Projeto de Preservação da Mata Atlântica. 2000.

SÃO PAULO (Estado). Secretaria dp Meio Ambiente do Estado de São Paulo. Parque Estadual Xixová-Japuí: Plano de Manejo - Fase I. São Paulo: SMA/ UNESP, 1997.

SATO, S. E.; CUNHA, C. M. L. O uso de técnicas morfométricas em áreas litorâneas: município de Mongaguá (SP). Estudos Geográficos, vol.5, p.1-20, 2007.

SIMON, A. L. H.; CUNHA, C. M. L. Elaboração do ábaco digital para a identificação de classes de declividade: aplicações na baixa bacia do rio Piracicaba - SP. In: Simpósio Brasileiro de Geografia Física Aplicada, 13., 2009, Viçosa. Anais... Viçosa: Universiadade Federal de Viçosa, 2009. p. 01-10.

SPIRODONOV, A. I. Principios de la metodologia e las invetigaciones de campo y el mapeo geomorfologico. Tradução: Isabel Alverez e C.D. Roberto del 
Busto. 3v. La Habana: Universidade de la Habana, Faculdad de Geografia, 1981.

SOUZA, T. A.; CUNHA, C. M. L. A importância do enriquecimento da drenagem para a analise morfometrica em areas de planície litorânea - o caso do Municipio de Praia Grande (SP). Seminário de Pos Graduacao em Geografia da Unesp Rio Claro, 9., 2009. Anais... Rio Claro: Universidade Estadual Paulista. 2009. p.1739-1753.

SUGUIO, K.; MARTIN, L. Cartas Geológicas do litoral paulista: Santos e Itanhaém. São Paulo: DAEE/ USP/FAPESP, 1978. 2 mapas. Escala:1:100.000.

TRICART, J. Principes et méthodes de la géomorphologie. Paris: Masson, 1965.

VERSTAPPEN, H. T.; ZUIDAM, R. A. van. System of geomorphological survey. Netherlands: Manuel ITC Textbook, vol.VIII. 1975.

ZACHARIAS, A. A. Metodologias convencionais e digitais para a elaboração de cartas morfométricas do relevo. 2001. 166f. Dissertação (Mestrado em Geociências) - Instituto de Geociências e Ciências Exatas, Universidade Estadual Paulista, Rio Claro, 2001. 